\title{
Enhanced Collagen Synthesis and Transcription by Peak E, a Contaminant of L-Tryptophan Preparations Associated with the Eosinophilia Myalgia Syndrome Epidemic
}

Hajime Takagi, ${ }^{\star}$ M. Sofia Ochoa, ${ }^{*}$ Linda Zhou, ${ }^{*}$ Todd Helfman, ${ }^{*}$ Hiroshi Murata, ${ }^{\star}$ and Vincent Falanga ${ }^{\star \neq}$

${ }^{*}$ University of Miami School of Medicine, Department of Dermatology and Cutaneous Surgery, Miami, Florida 33136; and ${ }^{\ddagger}$ Miami

Veterans Administration Hospital, Miami, Florida 33125

\begin{abstract}
The pathogenesis of the eosinophilia myalgia syndrome (EMS) remains unclear. Several abnormal constituents have been found in the L-tryptophan lots responsible for the illness, particularly, 1,1-ethylidenebis [L-tryptophan], also called peak $\mathrm{E}$ or EBT, and 3-phenylamino-alanine or peak 5. However, the role of these contaminants in the pathogenesis of EMS and in the development of fibrosis is unknown. We now report that peak $E$, a dimer of L-tryptophan, is a potent stimulus for human dermal fibroblast DNA and collagen synthesis. Peak E (0.1-1.0 $\mu \mathrm{M})$ increased DNA synthesis up to four-fold $(P=0.0001)$ in a dose-dependent manner $(r=0.987)$. When added to monolayer cultures for 2 to $24 \mathrm{~h}$, peak $\mathrm{E}(0.5$ to $100 \mu \mathrm{M})$ caused a progressive, more than threefold increase in alpha $1(\mathrm{I})$ procollagen mRNA levels and collagenous protein. No increase in procollagen mRNA levels was found after the addition of another major L-tryptophan contaminant, peak 5, or with L-tryptophan itself. Transient transfection with a 2.5 -kb alpha 1(I) procollagen promoter-luciferase construct showed that peak $E$ causes a twofold upregulation of promoter activity $(P$ $=0.022$ ). Contraction of collagen gels, consisting of human dermal fibroblasts incorporated into a type I collagen lattice, was enhanced two-fold by exposure to peak $E(P=0.001)$. We conclude that a major constituent of contaminated batches of L-tryptophan, peak $E$, is a potent stimulus for fibroblast activation and collagen synthesis. This stimulatory action of peak $\mathbf{E}$ may provide a direct mechanism for the development of fibrosis in EMS. (J. Clin. Invest. 1995. 96:2120-2125.) Key words: fibroblasts - L-tryptophan • EBT • fibrosis • EMS
\end{abstract}

\section{Introduction}

Eosinophilia myalgia syndrome (EMS) ${ }^{1}$ is a newly recognized disease which occurred in an epidemic form from 1989 to 1991

Address correspondence to Vincent Falanga, M.D, University of Miami School of Medicine, Department of Dermatology, P.O. Box 016250 (R250), Miami, Florida 33136. Phone: 305-547-5959; FAX: 305-5476191.

Received for publication 22 December 1994 and accepted in revised form 26 July 1995.

1. Abbreviation used in this paper: EMS, eosinophilia myalgia syndrome.

J. Clin. Invest.

(C) The American Society for Clinical Investigation, Inc.

0021-9738/95/11/2120/06\$2.00

Volume 96, November 1995, 2120-2125 and was found to be associated with the ingestion of altered Ltryptophan preparations. Although the initial defining features were myalgia and unexplained peripheral blood eosinophilia, it was later recognized that EMS involves many organ systems and leads to a variety of clinical presentations (1-3). Approximately half the patients with EMS have developed cutaneous or internal organ fibrosis, often identical to that seen in several forms of scleroderma. Indeed, the clinical picture of many EMS patients closely resembles eosinophilic fasciitis (Shulman's syndrome $)(4,5)$.

The pathogenesis of EMS remains unclear. Several abnormal constituents have been found in the L-tryptophan lots responsible for the illness, particularly 1,1-ethylidenebis [L-tryptophan ], also called peak E or EBT, and 3-phenylamino-alanine or peak $5(6-8)$. However, the role of these contaminants in the pathogenesis of EMS and in the development of fibrosis is unknown. Recent reports have focused on a pathogenic role of peak $\mathrm{E}$, an unusual compound formed during the manufacturing of L-tryptophan and consisting of two tryptophan molecules joined by an ethylidene bridge between the two indole ring nitrogens. It has been shown that Lewis rats treated with peak E or with contaminated L-tryptophan develop immunopathological abnormalities and myofascial thickening (9). Most recently, intraperitoneal administration of peak $E$ in an experimental murine model has been shown to cause an inflammatory response and mast cell degranulation (10). We have hypothesized that peak $\mathrm{E}$ has direct stimulatory effects on fibroblast replication and synthetic activity and that it may play an important direct role in the pathogenesis of fibrosis in EMS. The results shown here support this hypothesis.

\section{Methods}

Fibroblast cultures. Cultures of human dermal fibroblasts were established as previously described (11) from biopsies of dorsal forearm skin of adult healthy donors. Five different fibroblast strains in passages 3 8 were used throughout the experiments. For experiments involving transfection and collagen gels, we used neonatal foreskin fibroblasts in the first two in vitro passages. Cultures were initiated from explants and passaged in T-75 flasks (Corning glass works, Corning, NY) and seeded in DME (Sigma Chemical Co., St. Louis, MO) and $10 \%$ fetal bovine serum (FBS) (GIBCO Laboratories, Grand Island, NY). For experiments, FBS was substituted with dialyzed and L-tryptophan-free fetal calf serum (HyClone serum; HyClone Laboratories, Logan, UT). Unless otherwise indicated, all experiments involving collagen measurements were done in the presence of freshly prepared $100 \mu \mathrm{M}$ ascorbic acid (Sigma Chemical Co.) added daily. Except when stated, experiments were carried out by replacing DME with RPMI free of L-tryptophan. Fibroblasts were grown and kept at $37^{\circ} \mathrm{C}$ in $5 \% \mathrm{CO}_{2}, 95 \%$ air. Experiments were done by washing monolayers with RPMI without serum and incubating the cultures overnight with $0.1 \%$ bovine serum albumin 
(Sigma Chemical Co.). After $24 \mathrm{~h}$ the monolayers were washed with L-tryptophan-free RPMI three times over two hours, at which time the experimental media were added. The experimental media tested included L-tryptophan (GIBCO BRL), peak E, and peak 5 (Showa Denko Co., Tokyo, Japan)

$\left[{ }^{3} \mathrm{H}\right]$ Thymidine uptake. Fibroblasts were seeded at 30,000 cells per $2 \mathrm{~cm}^{2}$ wells in DME supplemented with $10 \%$ FBS. After $24 \mathrm{~h}$, monolayers were washed with phosphate buffered saline (PBS, GIBCO BRL) and the medium was replaced with $1 \mathrm{ml}$ of DME and $0.5 \%$ HyClone serum. After an additional $24 \mathrm{~h}$, monolayers were washed with PBS and incubated for $24 \mathrm{~h}$ with $1 \mathrm{ml}$ of L-tryptophan-free RPMI, $0.5 \%$ Hyclone serum, and increasing concentrations of peak E (Showa Denko Co., Tokyo, Japan), which was prepared by dissolving it in $40 \mathrm{mM}$ or either $\mathrm{HCl}$ or $\mathrm{NaOH}$. The $\mathrm{pH}$ of the stock solution of peak $\mathrm{E}$ in $\mathrm{HCl}$ was measured at 2.03 , and this was quickly and completely neutralized to 7.34 by addition to culture media in the concentrations of peak $\mathrm{E}$ tested $(0.1-100 \mu \mathrm{M})$. Next day, cultures were each pulsed for $4 \mathrm{~h}$ with $2 \mu \mathrm{Ci}$ of methyl- $\left[{ }^{3} \mathrm{H}\right]$ thymidine $(86 \mathrm{Ci} / \mathrm{mmol}$; Amersham Corp., Arlington Heights, $\mathrm{IL})$. Measurements of $\left[{ }^{3} \mathrm{H}\right]$ thymidine uptake were done as previously described (12).

RNA extraction and Northern analysis. Total cellular RNA from cells was isolated by extraction in guanidium isothiocyanate, using the method of Chomczynski and Sacchi (13). It was then separated for Northern analysis on $1 \%$ agarose gels containing $5 \%$ formaldehyde, and transferred to a nylon membrane (Schleicher and Schuell, Keene, NH) in a gradient of $20 \times$ to $10 \times$ SSC. We used a $1.5-\mathrm{kb}$ EcoRI fragment of a cDNA probe complementary to the mature protein coding region of the alpha $1(\mathrm{I})$ procollagen gene (14). A 2.0 -kb beta-actin human cDNA probe was obtained from Clontech Laboratories (Palo Alto, CA), while GAPDH cDNA was from the American Tissue Culture Collection (ATCC, Rockville, MD). Probes were labeled with ${ }^{32} \mathrm{P}$ by random priming and used for Northern blot analysis as previously described (15). For RNA electrophoresis, $10 \mu \mathrm{g}$ of total RNA were loaded per lane, as measured by absorbance at $260 \mathrm{~nm}$. Confirmation of uniformity of RNA loading was obtained by staining the nylon blots with methylene blue (15). Northern hybridization was performed at $42^{\circ} \mathrm{C}$ in a solution containing $50 \%$ formamide, $6 \times$ SSC, $5 \times$ Denhardt's reagent, $0.5 \%$ SDS, salmon sperm DNA (Sigma Chemical Co.), and the labeled cDNA probe $\left(2 \times 10^{8} \mathrm{cpm} / \mathrm{mg}\right)$. The blots were washed at room temperature one time in $1 \times$ SSC, $0.1 \%$ SDS for $20 \mathrm{~min}$, followed by three washes at $68^{\circ} \mathrm{C}$ in $0.2 \times \mathrm{SSC}, 0.1 \%$ SDS for 20 min each. Autoradiography was generally carried out overnight at $-70^{\circ} \mathrm{C}$.

Transfection studies. The human alpha 1 (I) procollagen promoterCAT construct was a generous gift from Dr. Francesco Ramirez (Moun Sinai University, New York, NY) and has been previously described $(16,17)$. For these experiments, the construct was modified as follows The 2.5-kb promoter region was excised with BamHI from the p8-CAT vector and inserted in the BglII site of the polylinker region of the pGL2-Basic Vector (Promega, Madison, WI) immediately upstream of the luciferase gene. Proper construct orientation was determined by restriction enzyme analysis. The pGL2-Control Vector, which contains an SV-40 promoter and an SV-40 enhancer inserted into the structure of the pGL2-Basic Vector, served as a positive internal control for transfection. For transfection, neonatal foreskin fibroblasts (passage 2) were first grown in DME and 10\% FBS. The cells were then plated in $35-\mathrm{mm}$ tissue culture dishes $24 \mathrm{~h}$ before transfection. Transfection was performed as previously described (18). The optimal amount of plasmid DNA and lipofectin was determined empirically for each new lot of lipofectin and new plasmid DNA preparation. For these experiments, we used $2 \mu \mathrm{g}$ of plasmid DNA and $4 \mu \mathrm{l}$ of lipofectin (GIBCO BRL) diluted with ITS (Becton Dickinson Labware, Bedford, MA). $6 \mathrm{~h}$ later, the medium was changed to DME and $10 \%$ Hyclone serum. After overnight incubation, peak E (100 $\mu \mathrm{M})$ or control media were added for an additional $48 \mathrm{~h}$. In other experiments, several concentrations of L-tryptophan were tested using the same experimental conditions. Cell extracts were prepared using a cell culture lysis reagent and a luciferase assay system (Promega) according to the manufacturer's protocol. Lu-

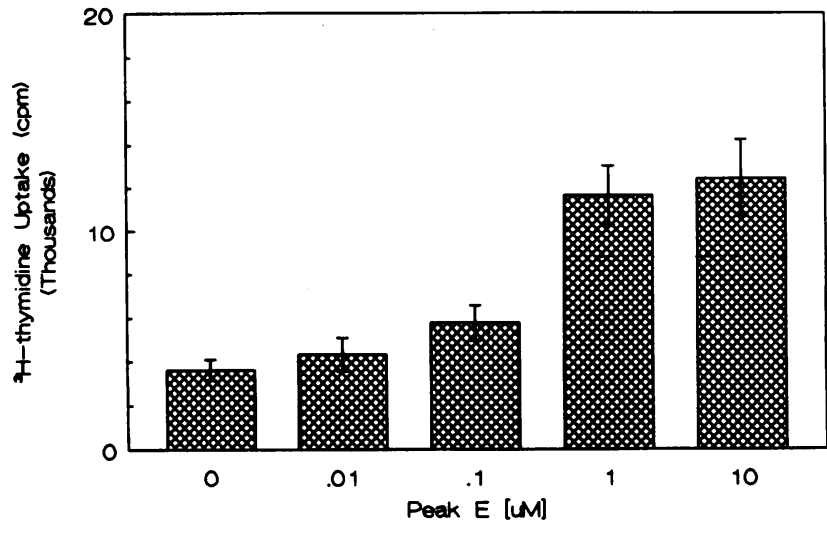

Figure 1. Peak E enhances DNA synthesis in human dermal fibroblasts. $\left[{ }^{3} \mathrm{H}\right]$ Thymidine uptake was measured $24 \mathrm{~h}$ after exposure to increasing concentrations of peak $\mathrm{E}$. The results represent the mean \pm SD from quadruplicate wells.

ciferase activity, as measured by chemiluminescence, was normalized for protein concentration.

Measurements of collagenous protein. Cells were seeded in 96-well plates at a density of 20,000 per well in $0.2 \mathrm{ml}$ of DME supplemented with $10 \%$ FBS. After a $72 \mathrm{~h}$ incubation to obtain confluent cultures, the monolayers were washed twice with PBS and the medium was changed to $0.2 \mathrm{ml}$ of RPMI containing the experimental reagent (either peak E or L-tryptophan), $3 \%$ HyClone serum, $50 \mu \mathrm{g} / \mathrm{ml}$ of freshly prepared ascorbic acid, $50 \mu \mathrm{g} / \mathrm{ml}$ beta-aminopropionitrile, and $0.5 \mu \mathrm{Ci}$ of $\left[{ }^{3} \mathrm{H}\right]-$ proline ( $99 \mathrm{Ci} / \mathrm{mmol}$; Amersham Corp.). After $24 \mathrm{~h},\left[{ }^{3} \mathrm{H}\right]$ proline incorporation into pepsin-resistant, salt precipitable extracellular collagen was determined as previously described (19). Results were expressed as dpm of $\left[{ }^{3} \mathrm{H}\right]$ collagen per cell number, as determined with a hemacytometer.

Collagen gel contraction. These were prepared as previously described (20). Briefly, a solution of bovine collagen type I and III (Vitrogen 100; Celtrix Laboratories, Palo Alto, CA) was mixed with $3 \times$ RPMI containing $20 \mathrm{mM}$ Hepes buffer (Sigma Chemical Co.), HyClone serum, human neonatal foreskin fibroblasts, and $100 \mu \mathrm{M}$ peak E. Control gels were prepared without peak E and with or without 4 nM PDGF BB (Austral Biologicals, San Ramon, CA). In all cases, the final solution contained by volume $30 \%$ Vitrogen, $15 \% 3 \times$ RPMI, $45 \%$ RPMI with Hepes buffer, $10 \%$ HyClone serum plus fibroblasts (6.0 $10^{4}$ cells $/ \mathrm{ml}$ ) and experimental reagents (peak E or PDGF). Two $\mathrm{ml}$ of the solution were poured into $35-\mathrm{mm}$ wells of 6-well plates and incubated at $37^{\circ} \mathrm{C}$ in $95 \%$ air and $5 \% \mathrm{CO}_{2}$. To insure even contraction, the internal edges of the wells were rimmed with a thin spatula and the plates were gently shaken until the gels floated freely in each well. As gels were not perfectly round, gel contraction was measured daily by using the means of the major and minor axes as the diameter of the gel. All experiments were carried out in quadruplicate.

Statistical analysis. Data were entered in a computerized statistical analysis program (InStat; GraphPAD Software, San Diego, CA). The Student's $t$ test was used for parametric results, while linear regression analysis was employed to determine correlation coefficients. Statistical significance was defined as a $P$ value of 0.05 or less.

\section{Results}

The hypothesis tested in these experiments is that peak $\mathrm{E}$ is a direct stimulus for fibroblast activation. We first measured the effect of peak $E$ on fibroblast DNA synthesis. As shown in Fig. 1 , the addition of peak $\mathrm{E}(0.01-1.0 \mu \mathrm{M})$ to adult human dermal fibroblasts stimulated fibroblast DNA synthesis up to four-fold in a dose-dependent manner $(r=0.987 ; P=0.0001)$. We next 


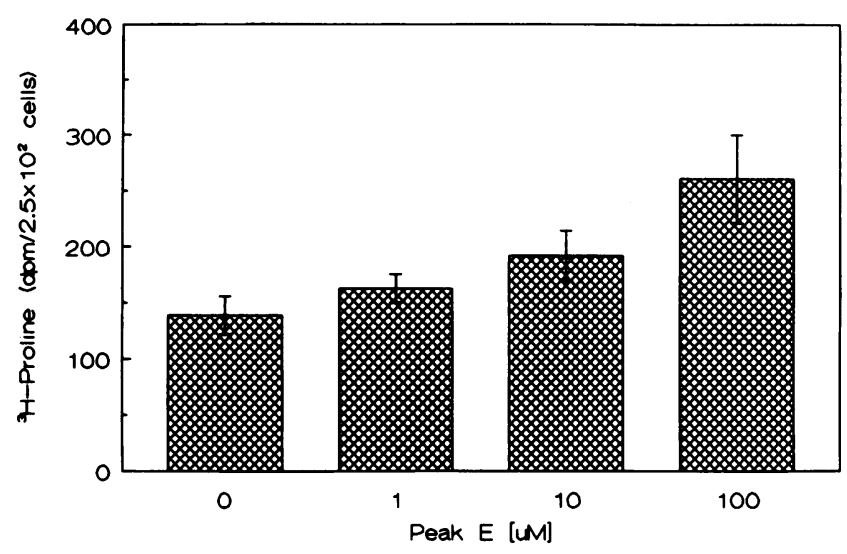

Figure 2. Peak E enhances the synthesis of collagenous protein. $\left[{ }^{3} \mathrm{H}\right]-$ Proline incorporation was measured $24 \mathrm{~h}$ after the addition of increasing concentrations of peak $\mathrm{E}$. The results represent the mean $\pm \mathrm{SD}$ from quadruplicate wells.

determined the effect of peak on collagenous protein. This was done by measuring $\left[{ }^{3} \mathrm{H}\right]$ proline incorporation into pepsin-resistant, salt precipitable extracellular collagen. Fig. 2 shows a representative experiment in which a dose-dependent $(r=0.944)$ up to twofold increase $(P=0.0001)$ in collagen synthesis was measured in response to peak $E$. These stimulatory effects of peak E on DNA and collagen synthesis are not likely to be the result of L-tryptophan formation from peak E hydrolysis. Indeed, a range of L-tryptophan concentrations failed to stimulate either DNA (Fig. 3) or collagen synthesis (Fig. 4). Type I collagen is the major collagen found in adult dermis, and its production is increased in EMS skin (21) and by EMS fibroblasts (22). In the next series of experiments, we found that exposure of fibroblasts to concentrations of peak $E$ ranging from 0.5 to $100 \mu \mathrm{M}$ caused a dose-dependent $(r=.817)$ more than threefold increase in alpha 1 (I) procollagen mRNA levels (Fig. 5). Upregulation of procollagen mRNA by peak $\mathrm{E}$ was found in four different experiments, was observed as early as two hours after the addition of peak E (Fig. 6), and persisted at 24 h (Figs. 5 and 6). Peak 5, another major contaminant found in EMS-associated L-tryptophan, had no stimulatory effect on

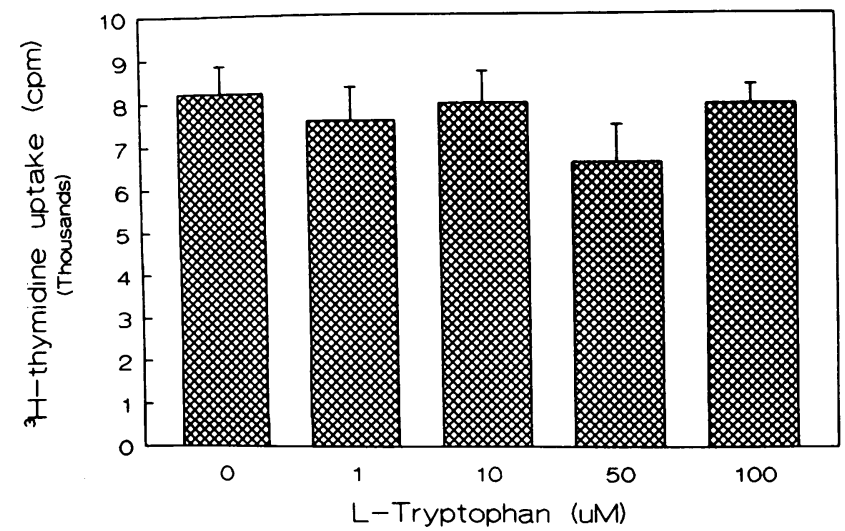

Figure 3. L-tryptophan does not stimulate DNA synthesis in human dermal fibroblasts. $\left[{ }^{3} \mathrm{H}\right]$ Thymidine uptake was measured $24 \mathrm{~h}$ after exposure to increasing concentrations of L-tryptophan.

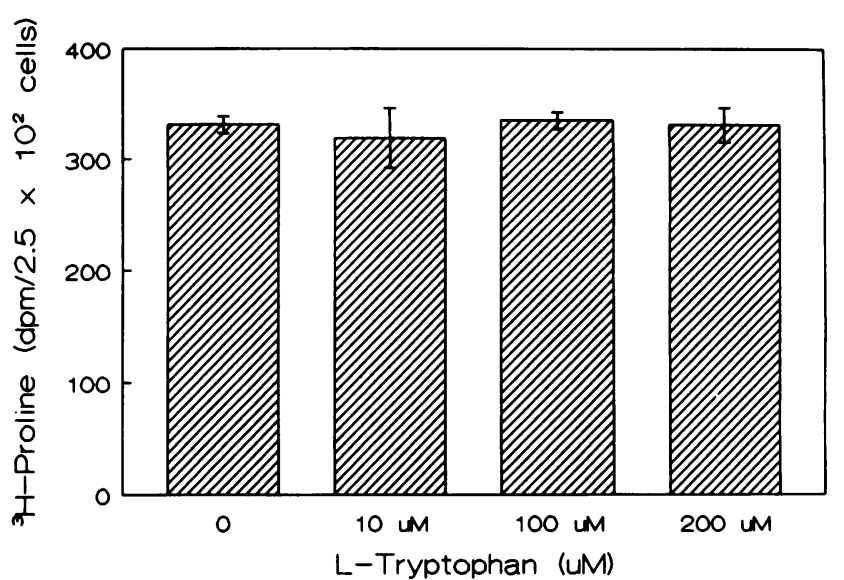

Figure 4. L-tryptophan fails to stimulate the synthesis of collagenous protein. $\left[{ }^{3} \mathrm{H}\right]$ Proline incorporation was measured $24 \mathrm{~h}$ after the addition of increasing concentrations of L-tryptophan. The results represent the mean \pm SD from quadruplicate wells.

alpha 1(I) procollagen mRNA levels (Fig. 7). At the highest concentrations tested ( $100 \mathrm{uM})$, peak 5 actually caused a small decrease in procollagen mRNA levels (Fig. 7). L-tryptophan itself and some of its normal metabolites have long been implicated in the pathogenesis of fibrosis, even before the EMS epidemic $(4,5)$. We therefore measured the direct effects of $L-$ tryptophan on alpha $1(\mathrm{I})$ procollagen mRNA levels. As in the representative experiment shown in Fig. 8, no stimulatory effect on procollagen mRNA levels was seen after exposure of fibroblast cultures to L-tryptophan. Lack of stimulatory activity of peak 5 and L-tryptophan was observed after 24 h (Figs. 7 and 8 ) and after $48 \mathrm{~h}$ (not shown).

The results shown above indicate that peak $\mathrm{E}$ is a potent stimulus for collagen synthesis. We next performed transient transfections of neonatal fibroblasts with a human $2.5-\mathrm{kb}$ alpha 1(I) procollagen promoter-luciferase construct. Neonatal fibroblasts were chosen for these experiments because they are

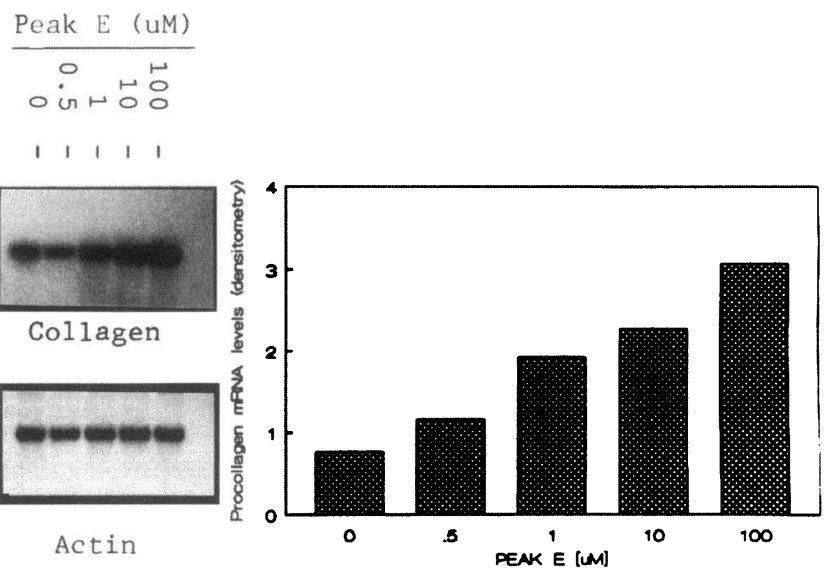

Figure 5. Increased steady state mRNA levels of alpha 1(I) procollagen in response to peak E. Human dermal fibroblasts were exposed to increasing concentrations of peak for $24 \mathrm{~h}$. The graph on the right shows densitometric readings for procollagen mRNA levels normalized for the expression of beta actin. 
Figure 6. Time-dependent increase in alpha 1(I) procollagen mRNA levels in response to peak E. RNA was isolated at the indicated time points after a single initial exposure of dermal fibroblast cultures to peak E ( 100 $\mu \mathrm{M})$. GAPDH mRNA levels were used to assess equal gel loading.

\section{GAPDH}

\section{Peak E \\ Alpha 1(I) procollagen}

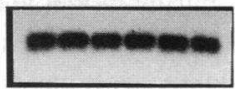

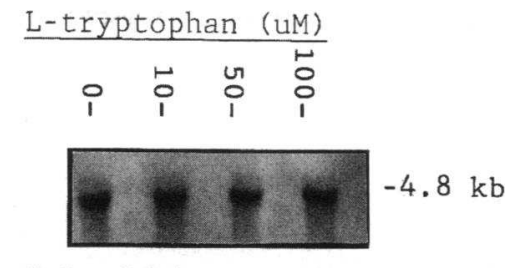

alpha 1 (I) procollagen

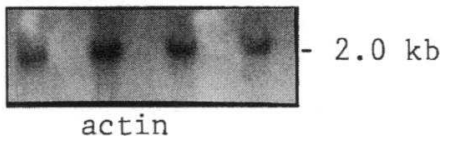

Figure 8. No change in alpha 1 (I) procollagen mRNA levels in response to L-tryptophan. Cultures were treated for $24 \mathrm{~h}$ with L-tryptophan in Ltryptophan-free RPMI.

more reproducibly transfected than adult fibroblasts and still allow us to test the alpha 1 (I) procollagen promoter region in relevant human cells. Fig. 9 shows that peak E enhanced promoter activity by almost twofold $(P=0.0226)$. The extent of stimulation of this alpha 1 (I) procollagen promoter region was comparable to that observed with the addition of $5 \mathrm{ng} / \mathrm{ml}$ of transforming growth factor-beta 1 (TGF-beta 1), which served as an additional positive control. As observed with DNA and collagen synthesis, increasing concentrations of L-tryptophan also failed to stimulate the activity of the alpha 1 (I) procollagen promoter (Fig. 10).

The above results show that peak E stimulates fibroblast DNA synthesis and collagen production. We next tested peak $E$ in an in vitro model of fibrosis that is dependent on the ability of fibroblasts to contract a collagen lattice in which they are incorporated (20). We prepared collagen lattices (gels) by seeding human dermal fibroblasts in a solution of type I collagen (20). First, we determined the cell number $\left(6.0 \times 10^{4}\right.$ per $\mathrm{ml})$ and serum concentration (10\%) required for optimal gel contraction (data not shown). We then exposed collagen gels to either peak E or PDGF in 10\% FBS. Platelet-derived growth factor BB (PDGF; $4 \mathrm{nM}$ ) was used as a positive internal control because this peptide growth factor is a known inducer of collagen gel contraction (23). As shown in Fig. 11, peak E increased gel contraction more than twofold by day $9(P=0.001)$. Between days 7 and 9 the effect of peak on collagen gel contraction was equivalent to that observed with PDGF $(P>0.05)$, although PDGF enhanced gel contraction at earlier time points with respect to both control and peak E (days 1 to $4 ; P<0.01$ ).

\section{Discussion}

A prominent feature of EMS has been the development of cutaneous and internal organ fibrosis. In situ hybridization studies have shown increased synthesis of several components of the extracellular matrix, including types I, III, and VI collagen in the affected dermis (21). Enhanced transcription of alpha 1(I) procollagen has been reported in fibroblast cultures established

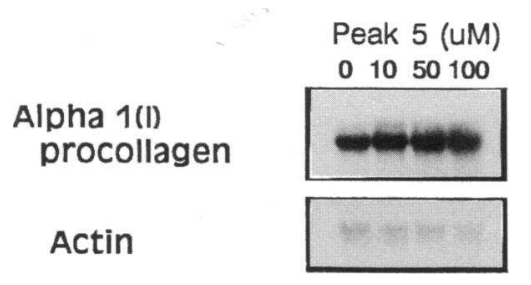

Peak 5 (UM) 01050100

Alpha 1(l)
procollagen

Actin
Figure 7. Peak 5 does not increase alpha 1 (I) procollagen mRNA levels. The results were obtained after $24 \mathrm{~h}$ of incubation with peak 5 . from the fibrotic skin of EMS patients (22). However, the pathogenesis of increased collagen synthesis in EMS remains unknown. In the present report, we have demonstrated that peak $\mathrm{E}$, a prominent abnormal constituent of L-tryptophan preparations causing EMS, is a potent stimulus for DNA and collagen synthesis in cultures of normal human dermal fibroblasts. We found peak $E$ to enhance DNA synthesis in a dose-dependent manner. As early as $2 \mathrm{~h}$ after its addition, peak $\mathrm{E}$ caused a dosedependent increase in collagenous protein and in alpha 1(I) procollagen mRNA levels. Conversely, L-tryptophan itself and peak 5, another prominent contaminant identified in EMS-associated L-tryptophan preparations, had no effect on procollagen mRNA levels. Peak E enhanced alpha 1(I) procollagen promoter activity and the contraction of collagen gels. Taken together, these results point to peak $\mathrm{E}$ as a potent and independently acting stimulus for fibroblast activation and collagen synthesis. Thus, peak E should be regarded as a possible pathogenic substance in the development of fibrosis in EMS. The ability of this compound to stimulate fibroblasts is important, for fibroblasts displaying markers of an activated phenotype are persistently present in the fascia or perimysium of EMS patients (24). The concentrations of peak $E$ found to stimulate collagen production in this report, as low as $1 \mu \mathrm{M}(0.44 \mu \mathrm{g} / \mathrm{ml})$ and as high as $100 \mu \mathrm{M}$, are well within the doses of peak E known to

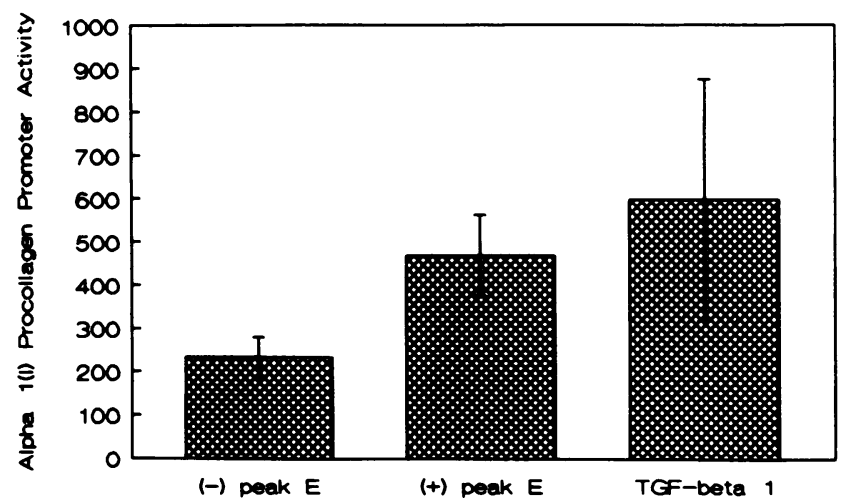

Figure 9. Peak E enhances alpha 1(I) procollagen promoter activity. Transient transfections were carried out by lipofection using a $2.5-\mathrm{kb}$ promoter-luciferase construct. Peak E ( $100 \mu \mathrm{M})$ was added $24 \mathrm{~h}$ after transfection and $48 \mathrm{~h}$ before assaying for luciferase. The results, which represent the mean \pm SEM of quadruplicate determinations from two separate experiments, are also compared to those obtained with the addition of TGF-beta $1(5 \mathrm{ng} / \mathrm{ml})$. 


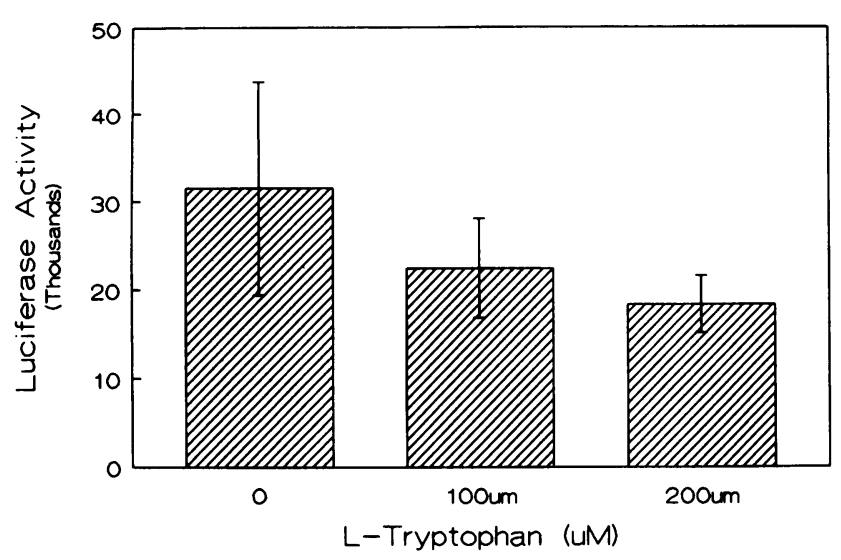

Figure 10. L-tryptophan does not upregulate alpha 1(I) procollagen promoter activity. Transient transfections were carried out by lipofection using a $2.5-\mathrm{kb}$ promoter-luciferase construct. Increasing concentrations of L-tryptophan were added $24 \mathrm{~h}$ after transfection and $48 \mathrm{~h}$ before assaying for luciferase. The results represent the mean \pm SEM of quadruplicate determinations.

cause disease in experimental animals and in patients with EMS $(9,10)$.

For a number of years, even before the EMS epidemic, Ltryptophan and some of its normal metabolites, such as serotonin and kynurenine, have been implicated in the development of fibrosis $(2,4,5)$. Injection of serotonin in animals has led to increased collagen deposition (25). Patients with EMS have been shown to have increased plasma levels of kynurenine, possibly as a result of increased activity of the enzyme indoleamine 2,3-dioxygenase (IDO) (2). Interestingly, supraphysiologic concentrations of L-tryptophan have been shown to stimulate collagenase synthesis and transcription in human skin fibroblasts (26). More recently, experimental approaches have focused on reproducing fibrosis and other features of EMS in animals by the administration of peak $E(9,27)$. Peak $E$ is the most prominent abnormal constituent of L-tryptophan lots

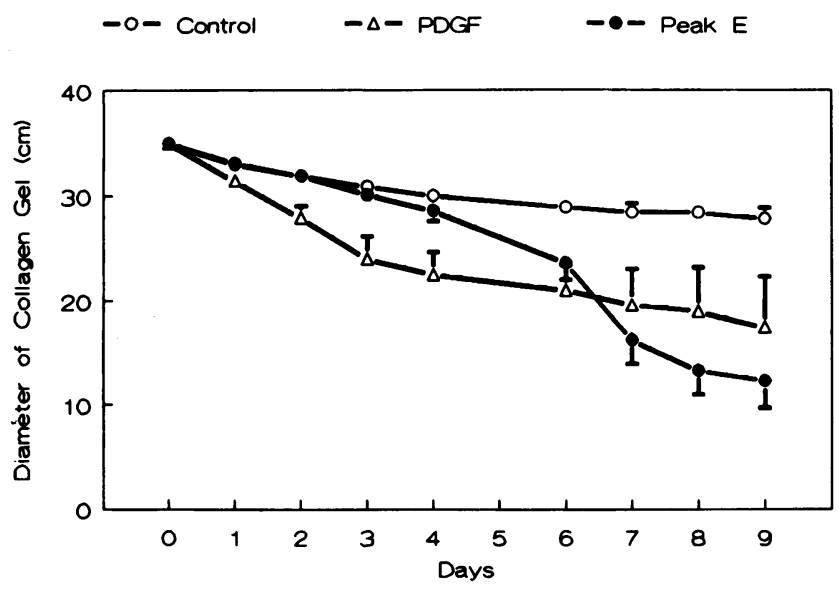

Figure 11. Increased collagen gel contraction in response to peak E. Gels, consisting of type I collagen and human dermal fibroblasts, were incubated in the presence of $10 \%$ FBS (control) with either peak E or PDGF BB (additional control). Gel diameter was measured daily. The results are the mean \pm SD from quadruplicate wells. associated with EMS, and it apparently formed during a change in the manufacturing process of L-tryptophan (6-8). Indeed, a close correlation has been found between the development of EMS and the presence of peak $\mathrm{E}$ in contaminated L-tryptophan preparations (8). Lewis rats treated with EMS-associated Ltryptophan or with peak E develop several immunopathological abnormalities and significant myofascial thickening (9). More recently, it has been shown that peak $\mathrm{E}$ administered intraperitoneally in an experimental murine model leads to mast cell activation (10). Immunologic activation in response to peak $\mathrm{E}$ appears to occur at multiple levels. It has been shown that peak $E$ leads to functional activation of eosinophils and interleukin 5 production by T-lymphocytes (28). This present report complements these recent immunologic studies by documenting a direct fibroblast-activating role of peak $\mathrm{E}$.

In conclusion, we have shown that peak $\mathrm{E}$, a major abnormal constituent of L-tryptophan preparations linked to the development of EMS, upregulates DNA and collagen synthesis in cultures of normal human dermal fibroblasts. This observation may provide an additional direct mechanism of fibrosis in EMS.

\section{Acknowledgments}

This work was supported by grants from the National Institutes of Health (AR-39658 and AR-42936), Showa Denko Company, Japan, and the Dermatology Foundation of Miami.

\section{References}

1. Hertzman, P. A., W. L. Blevins, J. Mayer, B. Greenfield, M. Ting, and G. J. Gleich. 1990. Association of the eosinophilia-myalgia syndrome with the ingestion of tryptophan. N. Engl. J. Med. 322:869-873.

2. Silver, R. M., M. P. Heyes, J. C. Maize, B. Quearry, M. Vionnet-Fausset, and E. M. Sternberg. 1990. Scleroderma, fasciitis, and eosinophilia associated with ingestion of tryptophan. N. Engl. J. Med. 322:874-881.

3. Clauw, D. J., D. J. Nashel, and P. Katz. 1990. Tryptophan-associated eosinophilic connective tissue disease. A new clinical entity? J. Am. Med. Assoc. 263:1502-1506.

4. Varga, J., and S. A. Jimenez. 1994. Chemical exposure-induced cutaneous fibrosis. Lessons from "Experiments of nature." Arch. Dermatol. 130:97-100.

5. Blauvelt, A., and V. Falanga. 1991. Idiopathic and L-tryptophan associated eosinophilic fasciitis before and after L-tryptophan contamination. Arch. Dermatol. 127:1159-1166.

6. Mayeno, A. N., F. Lin, C. S. Foote, D. A. Loegering, M. M. Ames, C. W Hedberg, and G. J. Gleich. 1990. Characterization of "Peak E," a novel amino acid associated with eosinophilia-myalgia syndrome. Science (Wash. DC). 250:1707-1708.

7. Hill, R. H. Jr., S. P. Caudill, R. M. Philen, S. L. Bailey, W. D. Flanders, W. J. Driskell, M. L. Kamb, L. L. Needham, and E. J. Sampson. 1993. Contaminants in L-tryptophan associated with eosinophilia myalgia syndrome. Arch. Environ. Contam. Toxicol. 25:134-142.

8. Belongia, E. A., C. W. Hedberg G. J. Gleich, K. E. White, A. N. Mayeno, D. A. Loegering, S. L. Dunnette, P. L. Pirie, K. L. MacDonald, and M. T. Osterholm. 1990. An investigation of the cause of the eosinophilia-myalgia syndrome associated with tryptophan use. N. Engl. J. Med. 323:357-365.

9. Love, L. A., J. I. Rader, L. J. Crofford, R. B. Raybourne, M. A. Principato S. W. Page, M. W. Trucksess, M. J. Smith, E. M. Dugan, M. L. Turner, E. Zelazowski, P. Zelazowski, and E. M. Sternberg. 1993. Pathological and immunological effects of ingesting L-tryptophan and 1,1'-ethylidenebis(L-tryptophan) in Lewis rats. J. Clin. Invest. 91:804-811.

10. Silver, R. M., A. Ludwicka, M. Hampton, T. Ohba, S. A. Bingel, T. Smith, R. A. Harley, J. Maize, and M. P. Heyes. 1994. A murine model of the eosinophilia-myalgia syndrome induced by $1,1^{\prime}$-ethylidenebis (L-tryptophan). J. Clin. Invest. 93:1473-1480.

11. Falanga, V., S. W. Qian, D. Danielpour, M. H. Katz, A. B. Roberts, and M. B. Sporn. 1991. Hypoxia upregulates the synthesis of TGF- $\beta 1$ by human dermal fibroblasts. J. Invest. Dermatol. 97:634-637.

12. Falanga, V., M. W. Katz, R. Kirsner, and A. Alvarez. 1992. The effects of endothelin-1 on human dermal fibroblast growth and synthetic activity. J. Surg. Res. 53:515-519. 
13. Chomczynski, P., and N. Sacchi. 1987. Single-step method of RNA isolation by acid guanidinium thiocyanate-phenol-chloroform extraction. Anal. Chem. 162:156-159.

14. Chu, M. L., J. C. Myers JC, M. P. Bernard, J. F. Ding, and F. Ramirez 1982. Cloning and characterization of five overlapping cDNAs specific for the human proalpha 1(I) collagen chain. Nucleic Acids Res. 10:5925-5935.

15. Falanga, V., T. A. Martin, H. Takagi, R. S. Kirsner, T. Helfman, J. Pardes, and M. Ochoa. 1993. Low oxygen tension increases mRNA levels of alpha 1(I) procollagen in human dermal fibroblasts. J. Cell. Physiol. 157:408-412.

16. Boast, S., M. W. Su, F. Ramirez, M. Sanchez, and E. V. Avvedimento 1990. Functional analysis of cis-acting DNA sequences controlling transcription of the human type I collagen genes. J. Biol. Chem. 265:13351-13356.

17. Jimenez, S. A., J. Varga, A. Olsen, L. Liye, A. Diaz, J. Herhal, and J. Koch. 1994. Functional analysis of human alpha 1(I) procollagen gene promoter. J. Biol. Chem. 269:12684-12691.

18. Felgner, P. L., T. R. Gadek, M. Holm, R. Roman, H. W. Chan, M. Went J. P. Northrop, G. M. Ringold, and M. Danielsen. 1987. Lipofection: a highly efficient, lipid-mediated DNA transfection procedure. Proc. Natl. Acad. Sci. USA. 84:7413-7417.

19. Webster, D. F., and W. Harvey. 1979. A quantitative assay for collagen synthesis in microwell fibroblast cultures. Anal. Biochem. 96:220-224.

20. Dans, M. J., and R. Isseroff. 1994. Inhibition of collagen lattice contraction by pentoxifylline and interferon-alpha, -beta, and -gamma. J. Invest. Dermatol. 102:118-121.

21. Varga, J., J. Peltonen, J. Uitto, and S. A. Jimenez. Development of diffuse fasciitis with eosinophilia during L-tryptophan treatment: demonstration of ele- vated type I collagen gene expression in affected tissues. Ann. Intern. Med. 112:344-352.

22. Varga, J., L. Li, and S. A. Jimenez. 1993. Increased type I collagen gene expression in L-tryptophan associated eosinophilia-myalgia syndrome skin fibroblasts. J. Rheumatol. 20:1303-1309.

23. Clark, R. A. F., J. M. Folkvord, C. E. Hart, M. J. Murray, J. M. McPherson. 1989. Platelet isoforms of platelet-derived growth factor stimulate fibroblasts to contract collagen matrices. J. Clin. Invest. 84:1036-1040.

24. Illa, I., S. Dinsmore, and M. C. Dalakas. 1993. Immune-mediated mechanisms and immune activation of fibroblasts in the pathogenesis of eosinophiliamyalgia syndrome induced by L-tryptophan. Human Pathol. 24:702-709.

25. MacDonald, R. A., S. L. Robbins, and G. K. Mallory. 1958. Derma fibrosis following subcutaneous injections of serotonin creatinine sulphate. Proc. Soc. Exp. Biol. Med. 97:344-347.

26. Varga, J., L. Li, A. Mauviel, J. Jeffrey, and S. A. Jimenez. 1994. Ltryptophan in supraphysiologic concentrations stimulates collagenase gene expression in human skin fibroblasts. Lab. Invest. 70:183-191.

27. Crofford, L. J., J. I. Rader, M. C. Dalakas, R. H. Hill, Jr., S. W. Page, L. L. Needham, L. S. Brady, M. P. Heyes, R. L. Wilder, P. W. Gold, J. Illa, C. Smith, and E. M. Sternberg. 1990. L-tryptophan implicated in human eosinophiliamyalgia syndrome causes fasciitis and perimyositis in the Lewis rat. J. Clin. Invest. 86:1757-1763.

28. Yamaoka, K. A., N. Miyasaka, G. Inou, I. Saito, J.-P. Kolb, K. Fujita and S. Kashiwazaki. 1994. 1,1'-ethylidenebis (tryptophan) (peak E) induces functional activation of human eosinophils and interleukin 5 production from $\mathrm{T}$ lymphocytes: association of eosinophilia-myalgia syndrome with a L-tryptophan contaminant. J. Clin. Immunol. 14:50-60. 